\title{
Osteoid osteoma of calcar of femur in child: prophylactic fixation using PHILOS and excision
}

\author{
Mantu Jain 지 , Sunil Doki, Siddharth Pradhan, Sashikanta Panda
}

Department of Orthopaedics All India Institute of Medical Sciences, Bhubaneswar, Orissa, India

\section{Correspondence to Dr Mantu Jain; montu_jn@yahoo.com}

Accepted 30 May 2020

\section{DESCRIPTION}

Osteoid osteoma (OO) affects proximal femur in $20 \%-25 \%$ of cases. ${ }^{12}$ When they are intra-articular, they can mimic inflammatory synovitis and be difficult to diagnose. ${ }^{34} \mathrm{CT}$ scan is the imaging modality of choice. ${ }^{5}$ Various treatment modalities have been described in literature but surgical excision remains gold standard. ${ }^{67}$ Here, we present two cases of $\mathrm{OO}$ of proximal femur-treated en bloc resection after prophylactic fixation with proximal humerus internal locking system (PHILOS) plate in child and adolescence. This type of fixation provides complete removal and the plate is found to be countered to the bone as illustrated.

\section{Case 1}

An 11-year-old girl weighing $20 \mathrm{~kg}$ was diagnosed as $\mathrm{OO}$ of calcar region after clinical and radiological examination. Plain X-ray and CT scan showed sclerosis in anteromedial aspect of inferior right femoral neck with nidus (figure $1 \mathrm{~A}-\mathrm{C}$ ). In supine position, a prophylactic fixation was done using a PHILOS plate through a lateral incision and the lesion was exposed using a Smith-Peterson approach. After marking under $\mathrm{C}$-arm, first some holes were drilled and then a block was excised using an oscillating saw (figure 1D,E). Postoperatively, the child got relieved of her pain and the wounds healed uneventfully. The patient was stated to mobilise full weight bearing after 6 weeks. Follow-up radiographs at 6
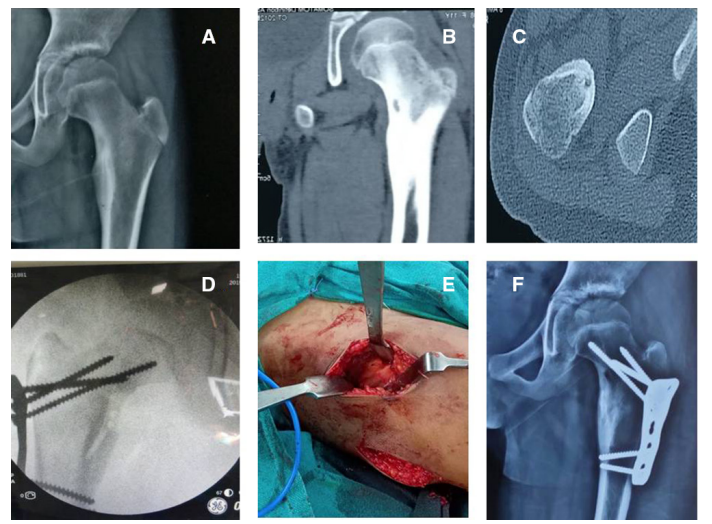

Figure 1 Radiograph of the right hip showing sclerosis anteromedial aspect of femoral neck with nidus surrounded by radiolucent rim in (A); CT scan images demonstrating eccentric lytic lesion with reactive bone sclerosis $(B, C)$; intraoperative and intensifier images showing the PHILOS plate and excised calcar (D); surgical image showing double incision (E) and follow-up radiograph showing bone healing and implant in-situ in (F). PHILOS, proximal humerus internal locking system.

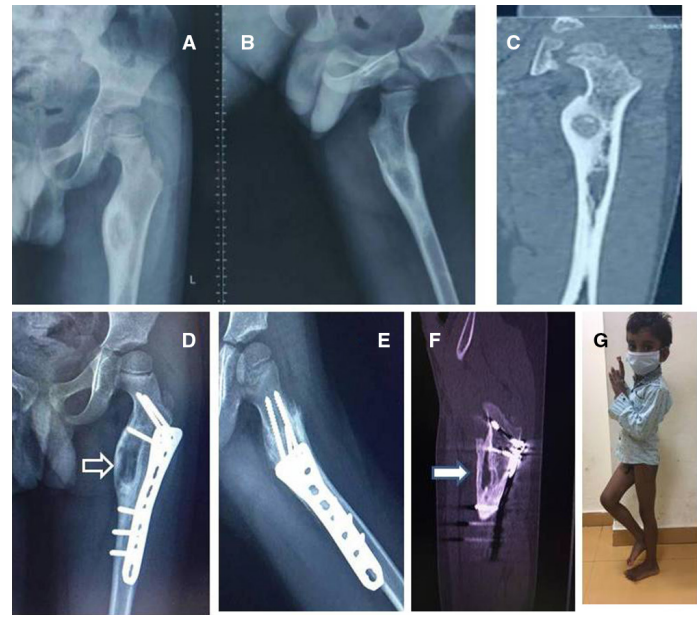

Figure 2 Antero-posterior and lateral radiographs of the left hip child showing sclerosis in the anteromedial aspect of the left lesser trochanter, nidus surrounded by the reactive bone of sclerosis (A, B); CT scan images showing eccentric lytic lesion with reactive bone sclerosis extending below lesser trochanter (C); followup radiograph showing bone healing (hollow arrow) in anteroposterior and frog lateral views with the proximal humerus internal locking system plate in-situ $(D, E)$; reduction of cavity in coronal CT cuts (F-solid arrow); and clinical picture showing single leg stance $(G)$.

months showed a healing bone and no recurrence or implant-related complications (figure $1 \mathrm{~F}$ ).

\section{Case 2}

A similar case in a 5 -year-old boy child who had been operated before elsewhere for OO presented with recurrence (figure $2 \mathrm{~A}-\mathrm{C}$ ). There was a medial scar on his left thigh suggestive of a medial approach and no other records available. This time using a Watson-Jones approach the PHILOS plate was slided and fixed. The limb was then external rotated and the periosteum was incised longitudinally. Two Hohman's retractor was placed superior and inferior to lesser trochanter and psoas tendon was displaced away from the working field. A cortical window was created and the leison was curetted. The biopsy confirmed OO. The patient was kept non-weight bearing for a month after which he started to mobilise. At his last follow-up at 8 months, he could stand painless on operated limb, radiographs show bridging callous (hollow arrow) and CT scans show reduction in cavity's size (solid arrow) were satisfactory (figure 2D-G).

$\mathrm{OO}$ are common in lower extremities but can be intra-articular in $0 \%-16 \%$. These can behave 
atypically like no night-pains or responsive to non-steroidal antiinflammatory drugs (NSAIDS) and even the nidus and cortical sclerosis could be absent. ${ }^{8}$ Hence, the diagnosis becomes challenging and often delayed. ${ }^{9}{ }^{10} \mathrm{CT}$ scan is usually confirmatory but MRI can show 'half moon sign' and the bone scintigraphy can display 'double density sign'. 1112

The aim of the treatment is to complete removal of the lesion. Latest technical modalities thermo/radiofrequency ablation are available in sophisticated centres and unaffordable to majority of poor patients in developing countries like ours. ${ }^{67}$ Recently, percutaneous drilling of the nidus either image intensifierguided/CT-guided has been described to safe, minimally invasive and cost-effective method though technically demanding. ${ }^{13}{ }^{14} \mathrm{An}$ en bloc surgical excision is gold standard technique but chances of iatrogenic fracture and use fixation devices particularly in the children remain a concern. ${ }^{15}$ The PHILOS plate used for proximal humerus fixation in adults had been demonstrated to fit well with multiple screw options saving the epiphysis and allowing for surgical manoeuvre medially. This can be done with a single or two incisions as demonstrated in our cases. We have not done bone grafting in any of the cases.

\section{Learning points}

- Osteoid osteoma of calcar is rare and difficult to diagnose.

- Surgical excision can be associated with iatrogenic fracture requiring prophylactic fixation.

- Proximal humerus internal locking system plate best suits the contour with multiple screw options.

Acknowledgements The faculties of Department of Radiology, AllMS, Bhubaneswar, for their inputs.

Contributors $\mathrm{MJ}$ and SD were operating surgeon in first instance whereas $\mathrm{MJ}, \mathrm{SPr}$ and SPa were in second instance. SPr and SPa followed up the case and SD reviewed the literature. MJ wrote the paper. All authors agree to content.
Funding The authors have not declared a specific grant for this research from any funding agency in the public, commercial or not-for-profit sectors.

Competing interests None declared.

Patient consent for publication Parental/guardian consent obtained.

Provenance and peer review Not commissioned; externally peer reviewed.

ORCID iD

Mantu Jain http://orcid.org/0000-0003-3848-4277

\section{REFERENCES}

1 Laurence $\mathrm{N}$, Epelman M, Markowitz Rl, et al. Osteoid osteomas: a pain in the night diagnosis. Pediatr Radiol 2012;42:1490-501.

2 Jaffe KA, Dunham WK. Treatment of benign lesions of the femoral head and neck. Clin Orthop Relat Res 1990;257:134???137-7.

3 Georgoulis AD, Papageorgiou CD, Moebius UG, et al. The diagnostic dilemma created by osteoid osteoma that presents as knee pain. Arthroscopy 2002;18:32-7.

4 Scalici J, Jacquel A, Mukish P, et al. Intra-Articular osteoid osteoma of the hip misdiagnosed by MRI: an unusual cause of unexplained hip pain. Orthop Traumatol Surg Res 2011;97:881-5.

5 Allen SD, Saifuddin A. Imaging of intra-articular osteoid osteoma. Clin Radiol 2003;58:845-52

6 Hoffmann R-T, Jakobs TF, Kubisch CH, et al. Radiofrequency ablation in the treatment of osteoid osteoma-5-year experience. Eur J Radiol 2010;73:374-9.

7 Raux S, Abelin-Genevois K, Canterino I, et al. Osteoid osteoma of the proximal femur: treatment by percutaneous bone resection and drilling (PBRD). A report of 44 cases. Orthop Traumatol Surg Res 2014;100:641-5.

8 Richardson MD, Taylor JAM. Intra-Articular osteoid osteoma in the femoral neck of an 18-year-old man: a case report. J Manipulative Physiol Ther 2009;32:245-50.

9 Cassar-Pullicino VN, Mccall IW, Wan S. Intra-Articular osteoid osteoma. Clin Radiol 1992;45:153-60.

10 Eggel Y, Theumann N, Lüthi F. Intra-Articular osteoid osteoma of the knee: clinical and therapeutical particularities. Joint Bone Spine 2007;74:379-81.

11 Davies M, Cassar-Pullicino VN, Davies AM, et al. The diagnostic accuracy of $\mathrm{Mr}$ imaging in osteoid osteoma. Skeletal Radiol 2002;31:559-69.

12 Klontzas ME, Zbis AH. Karantanas Ah. American Journal of Roentenoloy 2015;205:353-7.

13 Agashe M, Vaidya S, Dhamele J, et al. Ct-Guided percutaneous drilling of osteoid osteoma: a safe, minimally invasive and cost-effective method. Indian J Orthop 2020;54:194-9.

14 Abed ENA. Image intensifier-guided percutaneous drilling for osteoid osteoma of the proximal femur. Egypt Orthop J 2016;51:291-6.

15 Jaffe KA, Launer EP, Scholl BM. Use of fibular allograft strut in the treatment of benign lesions of the proximal femur. , 2002: 31, 575-8.

Copyright 2020 BMJ Publishing Group. All rights reserved. For permission to reuse any of this content visit

https://www.bmj.com/company/products-services/rights-and-licensing/permissions/

BMJ Case Report Fellows may re-use this article for personal use and teaching without any further permission.

Become a Fellow of BMJ Case Reports today and you can:

- Submit as many cases as you like

- Enjoy fast sympathetic peer review and rapid publication of accepted articles

- Access all the published articles

- Re-use any of the published material for personal use and teaching without further permission

Customer Service

If you have any further queries about your subscription, please contact our customer services team on +44 (0) 2071111105 or via email at support@bmj.com.

Visit casereports.bmj.com for more articles like this and to become a Fellow 